\title{
METROPOLIZACÃO: NOVAS TERRITORIALIDADES, NOVAS DINÂMICAS ESPACIAIS E NOVAS CONDICÕES DE URBANIZAÇÃO EM CIDADES DE MAIOR INFLUÊNCIA NO OESTE CATARINENSE
}

Claudio Machado Maia Aparicio Rolim ${ }^{2}$

\section{RESUMO}

O presente artigo discute o crescimento das regiões metropolitanas, assim como o contexto da região metropolitana de Chapecó e cidades influentes (Concórdia, Xanxerê, São Miguel do Oeste, Maravilha e Pinhalzinho) na rede urbana do Oeste Catarinense. Contribui-se ao debate acerca das cidades médias e os processos recentes de regionalização, a partir da consideração do processo de reestruturação das agroindústrias e a interdependência entre o urbano e o rural na região. Busca-se explicitar os reflexos desse processo para a reestruturação urbana e as transformações na forma das cidades em escala intraurbana. Para tanto, foram considerados dados econômicos e populacionais, a partir de fontes primárias e secundárias, além de trabalhos de campo, bem como contextualização do processo de formação da rede urbana na região. Embora evidente o dinamismo econômico caracterizado na região, alguns gargalos podem ser identificados, como a questão em torno da mobilidade e da oferta de transporte coletivo em termos de reduzir atrasos.

Palavras-chave: Urbanização. Cidades médias. Interdependência urbano-rural. Reestruturação urbana. Oeste catarinense.

\section{ABSTRACT}

This article discusses the growth of metropolitan areas, as well as the context of metropolitan Chapecó and influential cities (Concórdia, Xanxerê, São Miguel do Oeste, MaraviIha e Pinhalzinho) in the urban network of the western Santa Catarina. Contributes to the debate about the medium-sized cities and the recent processes of regionalization, from the consideration of the restructuring of the agricultural industries and the interdependence between urban and rural region. Seeks to clarify the consequences of this process for urban restructuring, and changes in the form of cities in intra-urban scale. Thus, we

\footnotetext{
${ }^{1}$ Doutor em Desenvolvimento Rural. Professor Titular da Unochapecó - Universidade Comunitária da Região de Chapecó. claudiomaia.dr@hotmail.com.br

${ }^{2}$ Acadêmico do curso de História da Unochapecó. Bolsista de Projeto de Pesquisa de Iniciação Científica (Associado - PIBIC/FAPE) da Unochapecó. ap.rolim@hotmail.com 
considered economic and population data from primary and secondary sources, in addition to field work, as well as contextualizing the formation process of the urban network in the region. Although obvious economic dynamism in the region characterized some bottlenecks can be identified, as the issue around mobility and offer transportation in terms of reducing time delays.

Keywords: Urbanization. Medium cities. Urban-rural interdependence. Urban restructuring. West of Santa Catarina.

\section{INTRODUÇÃO}

O crescimento das regiões metropolitanas na conformação contemporânea coloca problemas sociais, culturais e administrativos de políticas públicas cada vez mais importantes e impactantes. Conforme Benfatti, Queiroga e Silva (2010, p. 29),

[...] os cidadãos - ou, em sua maioria, apenas consumidores - atualmente têm concedido prioridade a uma abertura maior de suas possibilidades espaciais, ou seja, tem-se concedido a possibilidade de escolhas locacionais que, mesmo significando um gasto maior em termos de deslocamento cotidiano (residência, trabalho lazer), permite um número maior de escolhas.

Isso, por sua vez, coloca significação para uma passagem ou transição de uma sociedade simples para uma mais complexa. Esse movimento socioespacial tem influência significativa e diversificada sobre as diferentes escalas do território urbanizado. Ou seja, conforme Benfatti, Queiroga e Silva (2010), do ponto de vista da expansão urbana, das escolhas locacionais referentes à habitação e ao emprego, a população, sobretudo a metropolitana, amplia marcadamente seu raio de atuação, ação e influência. Isso leva a novas dimensões metropolitanas, novas possibilidades de comunicação e mobilidade, que geram novas formas de sociabilidade. Em tal contexto ou ambiente urbano que está em formação, as áreas ou localidades (cidades) em processo de formação urbana, os territórios urbanizados originados de uma concepção de tempo, que antes era mais estável, encontram-se deslocados em relação aos novos territórios resultantes dos movimentos da sociedade. Esses movimentos podem ser de expansão ou de fragmentação urbana em escalas mais amplas - metropolitanas, suprametropolitanas, regionais -, com localizações dos empregos mais distantes dos locais de residência, assim como novas formas de mobilidade, comunicação, redes em funcionamento, etc.

Conforme Boeri (2003),

[...] no lugar de cidades relativamente mais ordenadas e dentro de limites mais facilmente perceptíveis, lidamos com nebulosas urbanas e limites incertos, em que os deslocamentos não mais obedecem a fronteiras administrativas ou políticas. Esses fatos sugerem a idéia de uma sociedade urbana que estendeu enormemente no território seus movimentos cotidianos e cíclicos (BOERI, 2003, p. 364).

Tal contexto, por exemplo, encontra coerência e significado em parte considerá- 
vel da população urbanizada no entorno do município de Chapecó metropolizado, que, em grande parte, já se encontra em um processo de consumo muito caracterizado às compras a crédito, ao uso intensivo do automóvel, aos passeios ao shopping center, lan houses, bares e sobretudo aos cursos universitários noturnos.

Benfatti, Queiroga e Silva (2010) apresentam considerações que dão conta e bem podem caracterizar o que se observa no âmbito da região metropolitana de Chapecó. Conforme pesquisado pelos referidos autores, as formulações teóricas, as hipóteses conceituais a respeito dessa movimentação da sociedade, em termos culturais, de modo de vida e de sua distribuição espacial configuram ainda um terreno recente e pouco consolidado. De qualquer maneira, este artigo, apesar de integrar uma pesquisa mais ampla ${ }^{3}$, aborda algumas questões conceituais e caracterizadoras que apresentam uma perspectiva explicativa de parte da dinâmica regional específica da região metropolitana de Chapecó, de forma que se possa contribuir para uma reflexão teórica, conceitual e empírica.

Na figura 1, apresenta-se a região metropolitana de Chapecó, em que esse município é identificado como polo, a região identificada como metropolitana e a área de expansão da respectiva região metropolitana.

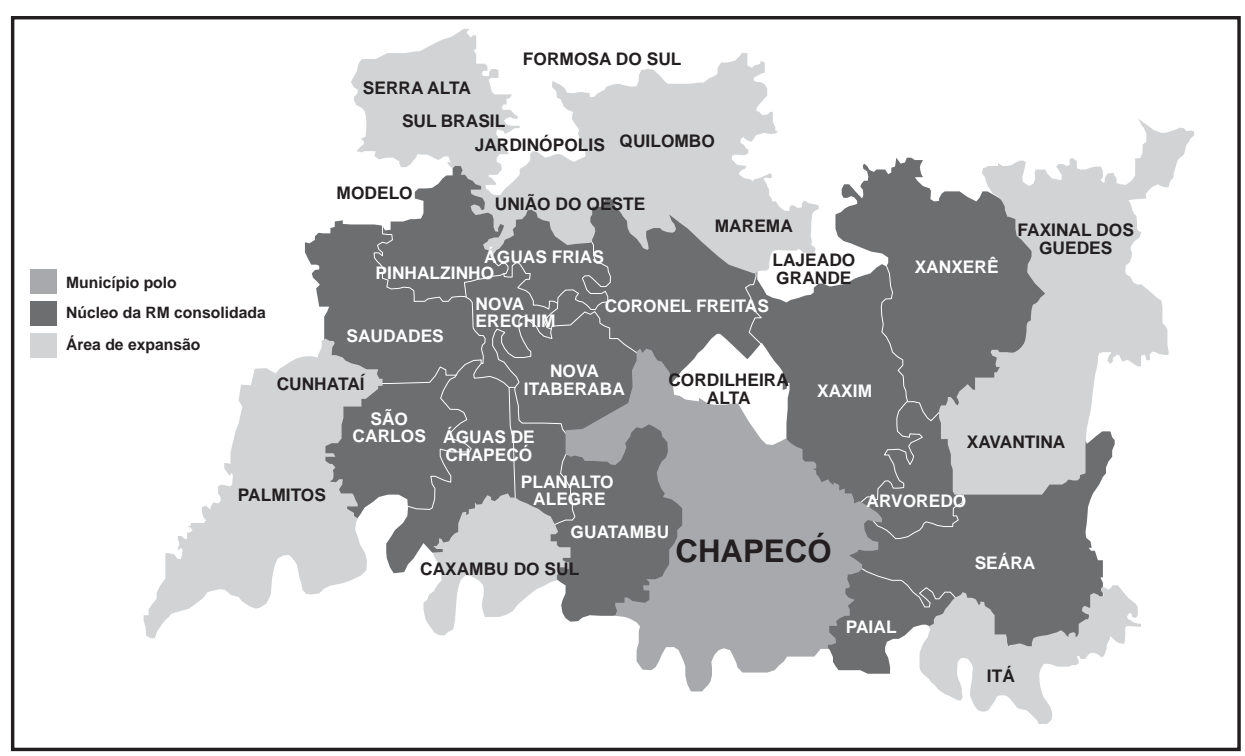

Figura 1: Mapa da região metropolitana de Chapecó ${ }^{4}$

Fonte: Tapado de Fresta (2013).

\footnotetext{
${ }^{3}$ Este artigo foi elaborado como contrapartida dos resultados parciais do Projeto de Pesquisa de Iniciação Científica (Associado - PIBIC/FAPE), Edital no 44/reitoria/2012, intitulado Dinâmicas Regionais e Novas Territorialidades em cidades de maior influência no Oeste Catarinense, realizado no âmbito da Universidade Comunitária da Região de Chapecó, Unochapecó.

${ }_{4}^{4}$ Criada pela Lei Complementar Estadual no 377, de 4 de abril de 2007. Reúne 16 municípios do estado de Santa Catarina em processo de conurbação, além de outros 9 que compunham a denominada área de expansão metropolitana, totalizando 25 municípios. $O$ núcleo metropolitano é composto pelos municípios de Chapecó, Xanxerê, Xaxim, Arvoredo, Paial, Seara, Guatambu, Planalto Alegre, Nova Itaberaba, Coronel Freitas, Pinhalzinho, Águas Frias, Nova Erechim, Águas de Chapecó, Saudades e São Carlos. A área de expansão metropolitana conta com os municípios de Itá, Xavantina, Faxinal dos Guedes, Marema, Quilombo, União do Oeste, Caxambu do Sul, Palmitos e Cunhataí.
} 
Conforme Ascher (1995), nos últimos 20 ou 30 anos, ganhou força uma tese relacionada às metrópoles tradicionais, especialmente as dos países europeus, formadas ainda na passagem dos séculos XIX para o XX, de que o período de crescimento dessas grandes cidades havia terminado.

Após décadas de crescimento urbano associado à metropolização, estaríamos na iminência de uma "inversão da tendência secular" da emigração campo-cidade.

Essa tese, dadas as especificidades do contexto brasileiro, chegou a repercutir no meio profissional e acadêmico, entre outros, pelo fato de que algumas das condições explicitadas poderiam ser verificadas para as grandes metrópoles brasileiras. Se estivesse correta, tal afirmação significaria um renascimento das cidades pequenas e médias. De qualquer maneira, tais condições se verificaram apenas parcialmente, tanto na Europa quanto no caso brasileiro.

Observa-se o decréscimo da população e da atividade apenas em alguns setores das metrópoles. O renascer das cidades pequenas e médias, apesar desse decréscimo apontado, não pode ser considerado de maneira generalizada, e sim como um fenômeno mais fortemente associado à localização dessas cidades na região metropolitana onde estão inseridas. Por exemplo, quando se analisam os dados da região metropolitana de Chapecó, sobretudo seu entorno, e especificamente as cidades de maior influência que compreendem os micropolos regionais as cidades de Concórdia, São Miguel do Oeste, Maravilha, Pinhalzinho e Xanxerê, observa-se uma tendência de crescimento, principalmente se consideradas as questões populacionais, de negócios, de comércio, enfim, algumas potencialidades ao processo de desenvolvimento.

\section{FORMAÇÃO DA REDE URBANA E O DESPONTAR DE CIDADES INFLUENTES NO OESTE CATARINENSE}

Para se pensar o papel das cidades estudadas, faz-se necessário relacionar a sua inserção regional nos processos de intermediação de troca de fluxos (bens, consumidores, serviços, informações, etc.), que perpassa a observação dialógica entre o urbano e o rural e as articulações transescalares que ocorrem entre o local e o global. Também há que se ter em conta diversos elementos e relações, as quais refletem especificidades que influenciam os municípios e a região, características que marcam a configuração da rede urbana e regional, as áreas de influência das cidades, bem como as estruturas sociais, organizacionais e econômicas existentes, que influem nos processos de territorialização, em constante transformação.

A fim de contextualizar a caracterização da rede urbana no Oeste Catarinense e de pensar os seus papéis de intermediação, faz-se pertinente considerar inicialmente o processo de conformação territorial e da rede urbana catarinense. As características do relevo e da influência sociocultural na estruturação fundiária, as divisões político-administrativas e de regionalização, bem como das condições produtivas e de infraestrutura contribuíram para a formação, no estado, de uma rede urbana composta por cidades de pequeno e médio porte (SIEBERT, 2001), de caráter multipolarizado (ANJOS, 2007), agrupadas em regiões que se organizam, dentre esses e outros fatores, sob a lógica de ramos dinamizadores da economia no estado. O Oeste Catarinense, dentro desse contexto, 
caracteriza-se pela marcada presença da atividade agroindustrial focada na produção de alimentos (suinocultura e avicultura e, mais recentemente, a bovinocultura de leite) e suas cadeias correlatas.

A evolução do papel de Chapecó, mais especificamente na rede urbana regional e nacional, pode ser apreendida a partir dos estudos do Instituto Brasileiro de Geografia e Estatística $^{5}$ (IBGE) sobre as relações de rede, hierarquia e região de influência que as cidades exercem umas sobre outras. Uma breve análise da inserção de Chapecó nos estudos realizados (1966, 1978, 1993 e 2008) aponta para a crescente influência da cidade no Oeste Catarinense, configurando como a mais influente capital regional (nível B), desde o meio oeste do estado até a fronteira, ligando-se à rede urbana de Curitiba e Porto Alegre (IBGE, 2007). Como dito anteriormente, em estudo precedente, foram identificadas as cidades que, juntamente com Chapecó, figuravam como as mais influentes na região, e que são objetos de estudos de tal pesquisa.

A rede urbana no Oeste Catarinense resulta principalmente dos processos de reestruturação produtiva da agropecuária, dos investimentos de capitais locais e estatais para o crescimento da agroindústria, o processo de (des)concentração de unidades de produção e suas cadeias correlatas, bem como da inserção dessas atividades produtivas nas dinâmicas econômicas internacionais, incorporando padrões de produção e de consumo globalizados. Associada a esse processo, a cadeia produtiva atrelada à agroindústria também se diversificou e se instalou em Chapecó e na região de modo representativo.

\section{3 (RE)ESTRUTURAÇÃO PRODUTIVA E (RE)ESTRUTURAÇÃO URBANA NO OESTE CATARINENSE E O CRESCIMENTO POPULACIONAL}

O processo de estruturação urbana e regional do Oeste Catarinense está pautado por sua formação socioeconômica. As atividades produtivas presentes, desde o século $\mathrm{XVIII}$, restringiam-se à pecuária e à erva-mate, as quais foram motivadoras, dentre outros aspectos, de diversos conflitos que se sucederam, envolvendo países e estados, até o início do século XX. Em 25 de agosto de 1917, Chapecó contava com uma extensão territorial que abrangia desde o meio oeste de Santa Catarina até a fronteira oeste, onde atualmente se situam os demais municípios estudados.

A ocupação territorial desta região, no século XX, ocorreu por meio da colonização empresarial, de modo que determinadas empresas ganharam a concessão para a exploração e comercialização das terras, que, em sua maioria, foram vendidas aos migrantes de descendentes europeus, oriundos das colônias gaúchas, a partir de 1920.

A atividade madeireira esteve associada a esse processo, mediante incentivo governamental e também devido ao interesse de assegurar a posse das terras, além da geração dos ganhos econômicos. Essa forma de colonização aos poucos consolidou o povoamento do Oeste Catarinense, marcado por inúmeros percalços, caracterizados pela tênue conexão da região ao resto do estado, pela precariedade e pela escassez de infraestrutura e peça falta de articulação aos mercados de modo geral. Assim, a partir da cultura de subsistência, um novo perfil socioeconômico começou a se delinear baseado na

${ }^{5}$ Denominado, doravante, apenas de IBGE. 
cultura da produção de excedentes, mesmo que de modo artesanal, levando à organização inicial do núcleo urbano da cidade de Chapecó, bem como à de outros pequenos focos de assentamentos. Todavia, os antigos habitantes - indígenas e caboclos -, expropriados de suas terras e de seu modo de vida, foram completamente excluídos do novo sistema econômico e fundiário que gradativamente se instalava (RENK, 1997).

$\mathrm{O}$ isolamento dos centros de comercialização e a necessidade crescente dos migrantes os obrigaram a transformar seus produtos também em busca de maior durabilidade, o que fomentou o ciclo da agroindustrialização mais adiante. A diversidade produtiva das propriedades, associada à distância e à dificuldade do transporte de grãos produzidos na região serviram de base para a dinâmica do sistema agroalimentar, já que os grãos produzidos serviam de alimento para a criação de pequenos animais, como galinhas e porcos, nas propriedades (BAVARESCO, 2005). A intermediação entre o produtor e o consumidor era exercida pelo comerciante que comprava os excedentes e os vendia nos estabelecimentos comerciais, agregando crescente influência econômica, de modo que foi a partir dela que foi gerado o capital investido na estruturação das agroindústrias. Fica evidente a interdependência entre o rural e o urbano, que pautam as relações de Chapecó e região até os dias atuais e cada vez mais fortemente.

Ao longo das décadas seguintes, houve o gradativo incremento das atividades industriais e da diversificação do comércio, impulsionando a consolidação do núcleo urbano de Chapecó e modificando a paisagem da cidade. Houve, sobretudo entre as décadas de 1950 e 1960, a emancipação de muitos municípios através dos desmembramentos, como se segue: Concórdia (1934), São Miguel do Oeste (1953), Xanxerê (1954), MaraviIha (1958) e Pinhalzinho (1961).

Nesse mesmo período, embora a economia da madeira ainda fosse significativa, a suinocultura começava a despontar como atividade econômica viável, que se adaptava às condições naturais e fundiárias existentes, respondendo, de modo promissor, à crise do período após Segunda-Guerra Mundial. O fomento à produção de matéria-prima pela produção dos excedentes contribuiu para a instalação dos primeiros frigoríficos para abate na região, como a Sadia, a Perdigão, a Chapecó Industrial e a Cooperativa Central Oeste Catarinense, visando ao mercado de São Paulo e do Rio de Janeiro.

Já na década de 1960, houve as primeiras experiências de integralização do produtor rural, que, mais tarde, marcariam o processo de reestruturação da agroindústria com vistas à expansão de mercado, o que provocou impactos urbanos e regionais pela exclusão de muitos produtores rurais que não se adequaram à modernização do processo produtivo. A partir da década de 1960, as transformações urbanas começaram a tomar maior vulto, expressas pela melhor estruturação, com a instalação de equipamentos urbanos e de instituições públicas, reforçando o papel regional de Chapecó, inclusive pelo considerável incremento trazido por obras viárias que atenuaram o isolamento da região.

O avanço da agroindustrialização nessas décadas ocorreu, em parte, também pelo incentivo financeiro do Estado, na época tomado pelos militares, além de outros fatores favoráveis, como as condicionantes naturais, a pequena propriedade diversificada, a base da agricultura familiar e a cultura do trabalho e da acumulação imbuída no migrante. Outro fator determinante foi a implementação do denominado "modelo de integração", que foi a forma encontrada para a manutenção da fragmentação dos agriculto- 
res em suas unidades produtivas, simultaneamente à sua "integração" a uma cadeia de produção necessária à nova fase de desenvolvimento do capital. A partir dele, padrões de produção puderam ser preestabelecidos pela empresa, com a vantagem de manter o produtor sob o seu controle econômico e também ideológico, criando uma relação de dependência. Uma característica marcante da agroindústria, que a diferencia das demais empresas, é que nela é possível estabelecer um acirrado controle sobre outro produtor privado, no caso o agricultor, ditando regras de acordo com a necessidade de obtenção de matéria-prima no ritmo e no tempo que a empresa determina (ALBA, 2002).

Segundo os censos demográficos (IBGE, 2012), entre as décadas de 1960 e 1980, associado ao crescimento e à consolidação dos frigoríficos, houve também o considerável crescimento populacional das cidades estudadas. Entre as décadas de 1960 e 1970, Chapecó e Concórdia não tiveram aumento populacional considerável devido aos desmembramentos ocorridos, porém os demais municípios cresceram consideravelmente. Maravilha, por exemplo, mais que dobrou de população no período, passando de 7.352 para 17.889 habitantes. Nota-se que a cidade de Pinhalzinho não havia ainda sido criada. Nesse período, o perfil populacional era predominantemente rural, com uma média aproximada de $80 \%$ da população vivendo na área rural.

Entretanto, é entre as décadas de 1970 e 1980 que transformações urbanas mais evidentes ocorreram. Nessas décadas, Chapecó teve um acréscimo populacional de $68 \%$, passando de 49.865 para 83.765 habitantes. Quanto ao restante dos municípios estudados, São Miguel do Oeste teve o crescimento percentual na taxa de $64 \%$, muito próximo aos números de Chapecó, ao que se seguem Concórdia, com 30\%, Maravilha, com 26\%, Pinhalzinho, similar à anterior, com 25\%, e Xanxerê, com $21 \%$.

Como ocorreu ao longo do processo de urbanização brasileiro, foi nesse período que houve a inversão quanto ao local de moradia dos habitantes, da área rural para a urbana. No caso de Chapecó, em 1970, 59\% dos moradores estavam no campo, ao passo que, em 1980 , essa porcentagem baixou para $34 \%$, observando-se que a população urbana nesse período quase triplicou. Essa inversão também aconteceu com os municípios de Xanxerê, São Miguel do Oeste, Pinhalzinho. Nos demais casos, Concórdia e Maravilha, essa mudança quanto ao local de moradia ocorreu na década seguinte, entre 1980 e 1991.

Desde então, a população urbana só tem crescido, chegando a mais de $91,6 \%$ em Chapecó, em 2010, seguidas por Xanxerê (88,7\%), São Miguel do Oeste (88,3\%), Pinhalzinho (83,36\%) e Concórdia (80\%) (IBGE, 2012). Entre 2000 e 2009, os municípios cujas taxas médias anuais de crescimento estavam acima da média estadual e nacional eram Pinhalzinho (2,75\%), Maravilha (2,5\%) e Chapecó (1,9\%). As taxas mais baixas estavam entre São Miguel do Oeste (1\%), Concórdia (1,2\%) e Xanxerê (1,3\%) (SERVIÇO BRASILEIRO DE APOIO ÀS MICRO E PEQUENAS EMPRESAS $\left.{ }^{6}, 2010\right)$.

Todavia, esses dados de modo algum significam que o rural perdeu sua importância, já que essas cidades se revelam justamente na interação dialética entre o urbano e o rural. O urbano só é urbano pela presença do rural diretamente interligado a ele, tal como se percebe ao longo deste estudo.

De meados da década de 1980 à década seguinte, começaram também a surgir

${ }^{6}$ Denominado, doravante, apenas de SEBRAE. 
os impactos do crescimento da cadeia da agroindústria, que progressivamente se verticalizava, bem como as implicações da globalização e das políticas econômicas mundiais dominantes. Se, por um lado, a agroindústria baseada na região buscava se inserir no mercado internacionalizado, por outro, as atividades produtivas sofreram duramente pela perda de competitividade, gerando impactos sociais e ambientais nas escalas urbana e regional, provocados pela concentração e intensidade dessas mesmas dinâmicas produtivas (VIEIRA; CUNHA, 2002). Houve, então, grande concentração e centralização do capital no setor agroalimentar. Se, no início da década de 1970, existiam 23 frigoríficos em Santa Catarina, na década de 1980, restaram apenas sete grandes frigoríficos, incluindo as cooperativas (GIESE, 1991 apud ALBA, 2002). Um fato recente foi a incorporação da Sadia pela Perdigão, formando a Brasil Foods S. A. (BRF).

\section{CONSIDERAÇÕES FINAIS}

Uma parte dos estudos que embasam essa pesquisa se refere à análise na escala intraurbana das cidades aqui abordadas, a fim de compreender como as mesmas têm se conformado em função da (re)estruturação produtiva e urbana. No caso de Chapecó, essa etapa foi finalizada. Nos outros casos, estão em andamento. Entretanto, algumas considerações são apresentadas.

Quanto aos elementos estruturadores das cidades, de modo geral, fica evidente o papel que os eixos viários possuem no padrão de localização dos setores secundários e, sobretudo, do terciário, que está em expansão, direta ou indiretamente relacionado à cadeia produtiva da agroindústria. Nesse último caso, pode-se perceber mudanças significativas nos ramos das redes de supermercados, de lojas e de hotéis, que historicamente predominavam nas capitais locais e regionais, mas que atualmente começam a apresentar a entrada de capitais nacionais e internacionais, como é o caso da instalação da rede Wallmart e de hotéis IBIS, além do shopping center da marca Pátio, em Chapecó, reforçando o seu papel de cidade do consumo ao possuir o primeiro desse tipo de empreendimento na região.

Outro ramo em expansão é o educacional, com a chegada e expansão de universidades públicas, como a Universidade Federal da Fronteira Sul, em Chapecó, e de muitas outras instituições privadas provenientes de redes nacionais e regionais, não só em Chapecó como em algumas outras cidades estudadas. Na área de serviços da saúde, Chapecó permanece como referência microrregional, apesar da oferta do serviço público dar indícios de estar bastante aquém da demanda, o que tem aberto espaço para a provisão dos serviços privados.

Todos esses setores dinâmicos ligados ao terciário estabelecem, através de sua localização nas cidades, vetores de expansão e valorização imobiliária. Quanto à oferta habitacional, observa-se uma considerável expansão do setor imobiliário, decorrente do dinamismo econômico descrito anteriormente, restrito principalmente a capitais locais e regionais. Com a oferta de créditos oriundos dos programas nacionais de financiamento, como o Minha Casa, Minha Vida, tem havido um boom imobiliário em todas as cidades. Todavia, entre os imóveis de padrão pretensamente destinados às camadas populares, as ofertas, em geral, não são inferiores a $\mathrm{R} \$ 100.000,00$ por imóveis que apresentam 
qualidade arquitetônica e urbanística duvidosa. Os imóveis de padrão médio e alto têm atingido, respectivamente, em torno de $\mathrm{R} \$ 280.000,00$ e $\mathrm{R} \$ 500.000,00$, o que não difere em muito dos preços em algumas capitais de estado, como Curitiba e Porto Alegre.

Dessa maneira, o dinamismo econômico mostra sua outra face quando despontam as desigualdades socioespaciais. Muito embora o Índice de Desenvolvimento Humano (IDH) não esteja abaixo da média nacional na maioria dos casos, as taxas de incidência de pobreza sobre o conjunto da população consideradas pelo IBGE em 2003 (SEBRAE, 2010) são bastante expressivas, a saber: Chapecó (33,8\%), Concórdia (28,8\%), Xanxerê (32,2\%), São Miguel do Oeste (30\%), Maravilha (28,1\%) e Pinhalzinho $(30,8 \%)$. Essa observação vem ao encontro de nota divulgada pelo IBGE, baseada nos indicadores Sociais Municipais 2010 (IBGE, 2011), afirmando que a incidência de pobreza é maior nos municípios de porte médio.

Sobretudo no caso de Chapecó, o crescimento populacional, causado pela busca por emprego e pelo êxodo das áreas rurais, fruto dos processos de modernização da agroindústria, não ocorreu de forma assistida, em termos de provimento de políticas públicas sociais. As consequências do abrupto adensamento do espaço da cidade podem ser constatadas.

Quando houve o maior crescimento da cidade, o município não possuía condições para viabilizar e prover a cidade na mesma rapidez com que consolidava o seu núcleo urbano, além do fato de que, naquela época, não era preocupação corrente dos poderes públicos o enfrentamento da exclusão social. Dessa forma, a desigualdade socioespacial já se fazia evidente na paisagem da cidade, com a formação de bairros operários sem infraestrutura, assentamentos precários e o despejo de populações excluídas em guetos que carregam até hoje o estigma da exclusão. Prova disso é que entre as décadas de 1970 e 1990 tem-se o período mais intenso de surgimento de novas áreas irregulares, chegando ao percentual de $77,3 \%$ das áreas existentes até 2011 , o que revela a falta de efetividade das políticas públicas habitacionais durante esse período.

No tocante à região metropolitana de Chapecó, sobretudo na análise dos territórios urbanizados em seu conjunto, verifica-se uma reorganização que favorece as cidades menores e cada vez mais situadas dentro de um mesmo mecanismo de funcionamento metropolitano, ou seja, de migrações alternadas e relações econômicas e sociais cotidianas em um mesmo espaço metropolitano. Trata-se de transformações que expressam uma recomposição funcional e social dos espaços metropolitanos (ASCHER, 1995). Então, inspirado em Benfatti, Queiroga e Silva (2010), observa-se a formação de uma entidade urbana nova, mas não uma megalópole como apontam os autores, especificamente no caso de Chapecó, um território que tem adquirido densidade técnico-científico-informacional e comunicacional.

Quanto aos parâmetros de mobilidade, é interessante referir que há um novo problema urbano. Há uma maior necessidade de vinculação a modalidades de deslocamento indutoras de um crescimento com certo grau de continuidade e coesão. No entanto, mais importante ainda, existe uma necessidade de maior oferta de transporte público e investimentos em meios de transportes alternativos que possam contribuir para reduzir o tempo de espera entre um horário e outro nos horários de transporte coletivo atualmente disponíveis. Além disso, a extensão e a descontinuidade das metrópo- 
les, em seu funcionamento contemporâneo, estão ligadas às redes viárias de circulação rápida e à disseminação do uso do automóvel e dos ônibus fretados, cuja circulação nas ruas dessas cidades localizadas na região metropolitana já se torna um novo problema urbano $^{7}$. Ou seja, devido a uma maior necessidade oferta de transporte coletivo urbano e intraurbano, que dê conta da mobilidade no âmbito da região metropolitana, nos períodos em que se registra um maior volume de tráfego, as infraestruturas de transporte nem sempre conseguem dar resposta a esse aumento, assistindo-se, então, a uma saturação quando a capacidade da infraestrutura é atingida e quando, a partir desse volume, a circulação começa a processar-se em regime forçado. Quando um veículo é adicionado a uma corrente de tráfego nessas condições, o resultado será o abrandamento das velocidades dos veículos que já se encontram na corrente de tráfego ${ }^{8}$.

\section{REFERÊNCIAS}

ALBA, Rosa S. Espaço Urbano: os agentes da produção em Chapecó. Chapecó: Argos, 2002.

ANJOS, F. A. O sistema urbano multi-polarizado de Santa Catarina. In: SPOSITO, M. E. B. (Org.). Cidades Médias: espaços em transição. v. 1. São Paulo: Expressão Popular, 2007. p. 413-437.

ASCHER, F. Métapolis ou l'avenir des villes. Paris: Odile Jacob, 1995.

BAVARESCO, P. R. Ciclos econômicos regionais: modernização e empobrecimento no Extremo Oeste Catarinense. Chapecó: Argos, 2005.

BENFATTI, Denio M.; QUEIROGA, Eugenio F.; SILVA, Jonathas M. Transformações da metrópole contemporânea: novas dinâmicas espaciais, esfera da vida pública e sistemas de espaços livres. Revista Brasileira de Estudos Urbanos e Regionais. v. 12. n. 1. p. 29-43, maio 2010.

BOERI, S. Apuntes para un programa de investigación. In: FORT, F.; ARC, M. J. (Orgs.). Mutaciones. Barcelona: Revue Centre d'Architectures, 2003.

IBGE. INSTITUTO BRASILEIRO DE GEOGRAFIA E ESTATÍSTICA. Censos Demográficos 1960, 1970, 1980, 1991, 2000, 2010. Disponível em: <http://www.ibge.gov.br>. Acesso em: 10 out. 2012.

Indicadores Sociais Municipais 2010: incidência de pobreza é maior nos municípios de porte médio Comunicação Social. 2011. Disponível em: <http://www. ibge.gov.br/home/presidencia/noticias/noticia_visualiza.php?id_noticia=2019\&id_ pagina=1>. Acesso em: 10 out. 2012.

Regiões de Influência das Cidades 2007. Rio de Janeiro: IBGE. Disponível em: <http://www.ibge.gov.br>. Acesso em: 10 maio 2013.

RENK, Arlene. A luta da erva: um ofício étnico no Oeste Catarinense. Chapecó: Grifos, 1997.

7 Aponta-se a necessidade de as Secretarias Municipais de Transporte estabelecerem regras específicas para atividade de fretamento e de circulação de veículos de transporte coletivo, de cargas, entre outros.

${ }^{8} \mathrm{O}$ congestionamento do tráfego é um problema crescente, o qual impõe à sociedade custos crescentes em termos de atraso de tempo, superiores mesmo aos custos operacionais necessários aos custos ambientais. 
SEBRAE-SC. SERVIÇO BRASILEIRO DE APOIO ÀS MICRO E PEQUENAS EMPRESAS-SC.

Santa Catarina em números. Florianópolis: Sebrae/SC, 2010. Disponível em:

<http://www.sebrae-sc.com.br/scemnumero/>. Acesso em: 13 out. 2012.

SIEBERT, C. Panorama do planejamento regional em Santa Catarina: da centralização à construção da solidariedade regional. In: (Org.). Desenvolvimento Regional em Santa Catarina: reflexões, tendências e perspectivas. Blumenau: Edifurb, 2001.

TAPADO DE FRESTA. Disponível em: <www.tapadodefresta.blogspot.com>. Acesso em: 13 out. 2013.

VIEIRA, P. F.; CUNHA, I. J. Repensando o Desenvolvimento Catarinense. In: (Orgs.). A Pequena produção e o modelo catarinense de desenvolvimento. Florianópolis: APED, 2002. 